\title{
Patient- and lesion-tailored algorithm of endovascular treatment for arterial occlusive disease of extracranial arteries supplying the brain: safety of the treatment at 30-day follow-up
}

\author{
Paweł Latacz' ${ }^{1}$ Marian Simka², Paweł Brzegowy³, Piotr Janas ${ }^{4}$, Marek Kazibudzki ${ }^{5}$, Piotr Pieniążek , \\ Andrzej Ochała ${ }^{7}$, Tadeusz Popiela ${ }^{3}$, Tomasz Mrowiecki ${ }^{1}$ \\ ${ }^{1}$ Department of Vascular Surgery, University Hospital, Krakow, Poland \\ ${ }^{2}$ Department of Angiology, Private Healthcare Institution SANA Outpatient, Pszczyna, Poland \\ ${ }^{3}$ Chair of Radiology, Jagiellonian University Medical College, Krakow, Poland \\ ${ }^{4}$ Department of Neurology, Murcki Hospital, Katowice, Poland \\ ${ }^{5}$ Department of Vascular Surgery, John Paul II Hospital, Krakow, Poland \\ ${ }^{6}$ Department of Interventional Cardiology, Jagiellonian University Medical College, John Paul II Hospital, Krakow, Poland \\ ${ }^{7} 3^{\text {rd }}$ Department of Cardiology, Medical University of Silesia, Katowice, Poland
}

Adv Interv Cardiol 2017; 13, 1 (47): 53-61

DOI: https://doi.org/10.5114/aic.2017.66187

\begin{abstract}
A bstract
Introduction: Although surgical endarterectomy remains the treatment of choice for carotid artery stenosis, stenting plays an important role as an alternative treatment modality, especially in high-risk patients. The actual safety profile associated with stenting procedures is probably better than that reported by randomized controlled trials.

Aim: To assess the safety of stent implantations in extracranial arteries supplying the brain, and also to identify risk factors associated with this procedure.

Material and methods: This was a post hoc analysis, with 30-day follow-up. We analyzed the results of treatment of 372 patients who underwent 408 procedures, 197 such procedures in asymptomatic, and 211 in symptomatic individuals. Stenting procedures were performed using a technique and armamentarium which were tailored to the type and anatomy of lesions.

Results: There were 6 (1.5\%) strokes, including 2 (0.5\%) major strokes, 1 ipsi- and 1 contralateral, and 4 (1.0\%) minor strokes. In asymptomatic patients there was $1(0.3 \%)$ minor stroke. Transient ischemic attacks occurred in $5(1.2 \%)$ patients. There were $2(0.5 \%)$ non-STEMI myocardial infarctions and $2(0.5 \%)$ non-stroke related fatalities. Risk factors of these adverse events were diabetes mellitus, lesions localized in a tortuous segment of the artery, embolic material in the filter and bilateral stenoses of carotid arteries. Additional risk factors in asymptomatic patients were renal impairment and advanced coronary artery disease; and in symptomatic patients, grade 3 arterial hypertension, dislipidemia, cigarette smoking and lesions requiring predilatation.

Conclusions: Stenting procedures of extracranial arteries supplying the brain, which are tailored to the type and anatomy of lesions, seem to be relatively safe.
\end{abstract}

Key words: carotid artery stenting, proximal protection system, distal protection system.

\section{Introduction}

Although surgical endarterectomy remains the treatment of choice for the management of carotid artery stenosis [1-4], carotid artery stenting (CAS) plays an important role as an alternative treatment modality in patients with high risk associated with open surgical treatment, and also those patients who present with carotid lesions of non-atherosclerotic etiology. Re- ports published by experienced centers demonstrated a high efficacy of this procedure and low complication rates [5-9]. On the other hand, randomized controlled trials that compared surgical endarterectomy with CAS revealed better results of open surgical repair, with higher complication rates in the CAS arm $[9,10]$. Thus, the actual safety profile associated with CAS and stenting procedures in other extracranial arteries sup-

Corresponding author:

Paweł Latacz MD, PhD, Department of Vascular Surgery, University Hospital, 3 Botaniczna St, 31-503 Krakow, Poland, phone: +48 501730853 , e-mail: pawlat@me.com

Received: 7.06.2016, accepted: 12.10.2016. 
plying the brain is probably better than that reported by randomized controlled trials and potentially may be at least non-inferior to open surgical repair of these blood vessels.

\section{Aim}

This post hoc analysis, with 30-day follow-up, aimed to assess the safety and efficacy of stent implantation for the treatment of atherosclerotic lesions in the extracranial arteries supplying the brain, and also to identify risk factors associated with this procedure.

Table I. Demographic and clinical characteristics of patients; number of patients: $N=372$, number of procedures: $N=408$

\begin{tabular}{|c|c|c|}
\hline Patients' characteristics & $N$ & $\%$ \\
\hline Mean age \pm SD & $69 \pm 8.3$ & \\
\hline Patients older than 80 years & 20 & 5 \\
\hline Male/female ratio & $238 / 134$ & $63 / 37$ \\
\hline Asymptomatic patients & 179 & 48 \\
\hline Risk factors & $N$ & $\%$ \\
\hline Stable coronary heart disease & 139 & 37 \\
\hline Arterial hypertension & 328 & 88 \\
\hline Diabetes mellitus type 2 & 112 & 30 \\
\hline Dislipidemia & 226 & 61 \\
\hline Cigarette smoking & 105 & 28 \\
\hline Renal impairment & 31 & 9 \\
\hline Peripheral artery disease & 50 & 13 \\
\hline $\begin{array}{l}\text { History of percutaneous coronary } \\
\text { angioplasty }\end{array}$ & 50 & 13 \\
\hline $\begin{array}{l}\text { History of coronary artery bypass graft } \\
\text { surgery }\end{array}$ & 32 & 9 \\
\hline History of cancer & 4 & 1 \\
\hline History of myocardial infarction & 92 & 25 \\
\hline Symptomatic carotid artery stenosis & 193 & 52 \\
\hline History of transient ischemic attack & 107 & 29 \\
\hline History of stroke & 86 & 23 \\
\hline $\begin{array}{l}\text { Bilateral stenosis of the internal carotid } \\
\text { artery }\end{array}$ & 134 & 36 \\
\hline Occlusion of the internal carotid artery & 51 & 14 \\
\hline $\begin{array}{l}\text { Bilateral occlusion of the internal or } \\
\text { common carotid arteries }\end{array}$ & 3 & 0.8 \\
\hline $\begin{array}{l}\text { Occlusion or stenosis of the subclavian } \\
\text { artery }\end{array}$ & 34 & 9 \\
\hline Stenosis of the vertebral artery & 52 & 14 \\
\hline Occlusion of the brachiocephalic trunk & 2 & 0.5 \\
\hline
\end{tabular}

\section{Material and methods}

We analyzed the results of treatment of 372 consecutive patients (134 women and 238 men) who were managed by our team at departments of vascular surgery from March 2011 to December 2015. Patients were aged $69 \pm 8.3$ years, and $20(5.4 \%)$ patients were aged more than 80 years. A total of 408 endovascular treatments with stent implantation have been performed, 197 such procedures in asymptomatic patients (group A), and 211 stenting procedures in symptomatic patients (group B). Some patients underwent endovascular treatment more than once. Demographic and clinical characteristics of patients, including potential risk factors, are presented in Table I, and a comparison between asymptomatic and symptomatic patients regarding these risk factors is provided in Table II.

Inclusion criteria for endovascular angioplasty with stent implantation comprised: more than $65 \%$ stenosis of the internal carotid artery (ICA) in symptomatic patients, more than $80 \%$ stenosis of the internal carotid artery in asymptomatic patients, and more than $90 \%$ stenosis of the vertebral, subclavian or proximal common carotid artery. Exclusion criteria for a stenting procedure comprised: highly calcified lesions, no adequate vascular access, contraindications for antiplatelet therapy and a lack of patient's consent. Symptomatic patients were managed at least 5 days after the neurologic event, preferentially on the $7^{\text {th }}-10^{\text {th }}$ day, depending on the findings of magnetic resonance imaging (MRI) of the brain and appearance of cerebral lesions revealed by this test; this was in line with recommendations from published studies [5, 8, 9].

The majority of stent implantations (367 procedures; 90.0\%) were performed for the treatment of lesions in the ICAs: 167 procedures in the right ICA (including one procedure with simultaneous treatment of coexisting tandem stenosis of the common carotid artery) and 200 stenting procedures of the left ICA. Other treatments were performed to address lesions in the brachiocephalic, subclavian and vertebral arteries; details are given in Table III.

Standard preprocedural management of patients comprised multidisciplinary assessment, including neurological, vascular and cardiologic consultations. Neurological assessment was performed at least before the procedure and on the first postprocedural day. Endovascular procedures were performed by well-trained interventionalists, with an expertise of over 1000 endovascular procedures already carried out.

Stent implantations were performed using the technique and armamentarium which were tailored to the type and anatomy of the lesion. The decision tree for such a choice included:

- anatomy of the arteries (type of the aortic arch, tortuousness of the carotid arteries, patency of these arteries); 
Table II. Risks factors in asymptomatic vs. symptomatic patients

\begin{tabular}{|c|c|c|c|}
\hline Risk factor & $\begin{array}{c}\text { Asymptomatic patients } \\
\text { (197 procedures) }\end{array}$ & $\begin{array}{c}\text { Symptomatic patients } \\
\text { (211 procedures) }\end{array}$ & $P$-value \\
\hline Mean age $( \pm$ SD) & $68.5 \pm 7.2$ & $69.1 \pm 9.14$ & NS \\
\hline Patients aged $>80$ years & 5 & 14 & NS \\
\hline Patients aged $<60$ years & 18 & 18 & NS \\
\hline Male patients & 117 & 121 & NS \\
\hline Stable coronary heart disease & 75 & 64 & $<0.05$ \\
\hline Congestive heart failure & 5 & 11 & NS \\
\hline Cigarette smoking & 49 & 56 & $<0.05$ \\
\hline Diabetes mellitus type 2 & 51 & 61 & $<0.05$ \\
\hline Arterial hypertension & 155 & 173 & $<0.05$ \\
\hline Dislipidemia & 112 & 118 & NS \\
\hline Renal impairment & 12 & 19 & NS \\
\hline Peripheral arterial disease & 23 & 27 & NS \\
\hline History of myocardial infarction & 48 & 44 & NS \\
\hline History of percutaneous coronary angioplasty & 20 & 31 & $<0.05$ \\
\hline History of coronary artery bypass graft surgery & 18 & 15 & NS \\
\hline Aortic or mitral valve disease & 2 & 0 & NS \\
\hline Contralateral stenosis of the internal carotid artery & 45 & 61 & 0.06 \\
\hline Occlusion of the internal carotid artery & 15 & 36 & $<0.05$ \\
\hline Occlusion of the subclavian artery & 2 & 8 & NS \\
\hline Stenosis of the vertebral artery & 10 & 24 & $<0.05$ \\
\hline
\end{tabular}

NS - difference statistically not significant.

- characteristics of the lesion (stable/unstable, presence of calcifications, sonographic features, such as homo- or hyperechogenicity, presence of thrombus);

- coexistence of lesions in other arteries: carotid, vertebral, subclavian, brachiocephalic trunk or intracranial arteries;

- choice of vascular access: femoral, radial or brachial. Taking into account all four above-mentioned components, firstly the proper vascular access was chosen, usually a femoral or radial, rarely a brachial one. Then, the protection system was selected, either a proximal or distal one. In the case of a distal protection system, also the type and length of the filter, as well as the type and size of the introducer sheath, were chosen. Depending on the characteristics of the lesion, the design of the stent was selected: close-cell or open-cell, self-expandable or balloon-expandable. Finally, the size of the balloon dedicated for postdilatation of the stent was chosen. The endovascular procedure was considered to be successful if either the lesion was fully expanded or residual stenosis was less than $20 \%$.

Although a proximal protection system was the preferred one, in many patients it was necessary to use a distal system, primarily due to coexisting significant lesions in other arteries supplying the brain. For example, 106 (28.5\%) patients presented with bilateral stenoses of the ICAs, and 51 (13.7\%) other patients had at least one significant lesion in the vertebral or subclavian artery. Therefore, in the majority of cases we decided to apply a distal protection system: in asymptomatic

Table III. Location of the lesions treated $(N=408)$

\begin{tabular}{lcc}
\hline Artery & N & $\%$ \\
\hline Left internal carotid artery & 200 & 49 \\
\hline Right internal carotid artery & 167 & 41 \\
\hline Brachiocephalic trunk & 5 & 1.2 \\
\hline Right subclavian artery & 2 & 0.5 \\
\hline Left subclavian artery & 12 & 3 \\
\hline $\begin{array}{l}\text { Left vertebral artery } \\
\text { (including 4 intracranial lesions) }\end{array}$ & 11 & 3 \\
\hline Right vertebral artery & 5 & 1.1 \\
\hline Right common carotid artery & 1 & 0.2 \\
\hline Left carotid common artery & 5 & 1
\end{tabular}


patients such a system was used in 140 (71.1\%) cases and in symptomatic patients in 154 (73.0\%) cases, while a proximal protection system was used in 40 (20.3\%) asymptomatic and 57 (27.0\%) symptomatic patients. In a few patients presenting with stenoses of the subclavian artery there was no need for the use of a protection system. On the other hand, in 2 symptomatic patients we applied both proximal and distal protection systems.
Details regarding protection systems used are given in Table IV.

In 4 patients, due to symptomatic stenoses of the vertebral arteries, it was necessary to perform an intracranial endovascular angioplasty. In 2 such cases it was also necessary to implant a stent: a balloon-expandable drug-eluting stent in 1 patient and a Wingspan stent a self-expanding stent dedicated for intracranial lesions

Table IV. Characteristics of protection systems and stents utilized in 408 procedures (375 CAS and 33 other procedures) in asymptomatic vs. symptomatic

\begin{tabular}{|c|c|c|c|}
\hline Variable & $\begin{array}{l}\text { Asymptomatic patients } \\
\text { (197 procedures) }\end{array}$ & $\begin{array}{l}\text { Symptomatic patients } \\
\text { (211 procedures) }\end{array}$ & $P$-value \\
\hline Proximal protection systems: & 40 & 57 & 0.05 \\
\hline Mo.Ma (Medtronic, Minneapolis, MN, USA) & 36 & 50 & 0.05 \\
\hline Gore Flow Reversal System (Gore \& Associates, Inc., Flagstaff, AZ, USA) & 4 & 7 & NS \\
\hline Distal protection systems: & 140 & 138 & NS \\
\hline SpiderFX (Covidien, ev3 Endovascular, Inc., Plymouth, MN, USA) & 42 & 49 & NS \\
\hline Emboshield NAV6 (Abbott Vascular, Abbott Park, IL, USA) & 37 & 44 & NS \\
\hline FilterWire EZ (Boston Scientific, Natick, MA, USA) & 28 & 27 & NS \\
\hline RX Accunet (Abbott Vascular, Abbott Park, IL, USA) & 23 & 15 & NS \\
\hline FiberNet (Medtronic, Minneapolis, MN, USA) & 6 & 0 & NS \\
\hline Angioguard (Cordis, Fremont, CA, USA) & 2 & 1 & NS \\
\hline Defender (Medtronic, Minneapolis, MN, USA) & 2 & 2 & NS \\
\hline \multicolumn{4}{|l|}{ Stents: } \\
\hline Precise (Cordis, Fremont, CA, USA) & 38 & 48 & 0.05 \\
\hline Carotid Wallstent (Boston Scientific, Natick, MA, USA) & 47 & 54 & 0.05 \\
\hline Xact (Abbott Vascular, Abbott Park, IL, USA) & 25 & 25 & NS \\
\hline Acculink (Abbott Vascular, Abbott Park, IL, USA) & 39 & 28 & 0.05 \\
\hline Cristallo Ideale (Medtronic, Minneapolis, MN, USA) & 31 & 36 & NS \\
\hline Roadsaver (Terumo, Tokyo, Japan) & 1 & 0 & NS \\
\hline Balloon-expandable stents & 15 & 11 & NS \\
\hline Drug-eluting stents & 1 & 9 & 0.05 \\
\hline Close-cell design stents & 104 & 115 & NS \\
\hline Open-cell stents & 93 & 96 & NS \\
\hline \multicolumn{4}{|l|}{ Vascular access: } \\
\hline Femoral & 193 & 205 & NS \\
\hline Radial & 2 & 5 & NS \\
\hline Brachial & 2 & 1 & NS \\
\hline \multicolumn{4}{|l|}{ Macroscopically visible embolic material in protection system: } \\
\hline Single plaque or thrombus & 15 & 28 & 0.05 \\
\hline A little debris & 2 & 8 & NS \\
\hline A lot of debris & 3 & 4 & NS \\
\hline
\end{tabular}

NS - difference statistically not significant. 
(Stryker Neurovascular, Fremont, CA, USA) - in the other patient. There were also 4 procedures that addressed lesions in the distal part ( 4 / $C 5$; cavernous/clinoid segments) of the ICA, including 1 case where a self-expandable covered stent was implanted. Also, 1 patient developed intraprocedural embolism of the right middle cerebral artery, which was successfully managed using the Solitaire revascularization device (ev3 Endovascular, Plymouth, MN, USA). There were no significant complications related to the endovascular armamentarium used, protection systems or the stents.

Patients presenting with arterial hypertension had their medications modified: calcium channel blockers, $\beta$-blockers and other potent antihypertensive drugs were not administered on the day of the endovascular procedure. If such a treatment modification was not possible, for example in patients with low ejection fraction, during the procedure we administered intravenously dopamine or dobutamine in order to minimize stimulation of the baroreceptors. In a case of peri- or postprocedural hypertension we administered intravenously $\alpha$ - or $\beta$-blockers instead of nitroglycerin. All the above-mentioned modifications did not apply in patients managed for stenoses of the vertebral arteries. Periprocedural bradycardia was managed with the administration of atropine, and 1 such patient additionally required 4-hour endocavitary pacing. We did not routinely perform coronary angiography before endovascular treatment of arteries supplying the brain [7].

Sonographic follow-up of the treated arteries was performed on the day of the procedure, and then after 1 and 6 months. Ninety-nine percent of the patients were available for 30-day follow-up. Patients were advised to report any neurological events that occurred during this period. This 30-day follow-up was primarily aimed at the assessment of safety of these endovascular procedures.

The primary endpoint was the proportion of patients who had stroke or stroke-related death. We included all types of strokes, both ipsi- and contralateral, as well as minor, major and fatal strokes.

Neurological symptoms were categorized as follows: transient ischemic attack, which was defined as an acute neurological deficit resulting from focal temporary cerebral or retinal ischemia that lasted less than $24 \mathrm{~h}$; stroke, which was defined as a new cerebrovascular event of ischemic or hemorrhagic etiology resulting in cerebral infarction and neurological deficit. Strokes were further classified as: minor - with neurological deficits lasting less than 30 days, or lasting longer than 30 days but presenting with a small deficit (National Institute of Health Stroke Scale up to 4 points); major - with neurological deficits lasting longer than 30 days, and fatal: as a stroke (ischemic or hemorrhagic) resulting in death.

The secondary endpoint was the proportion of patients who had myocardial infarction (both ST elevation myocardial infarction (STEMI) and non-STEMI events) or a death that was not caused by stroke. Death of any non-stroke cause was taken into account. In addition to demographic and clinical data of the patients, we analyzed angiographic characteristics, such as presence of coexisting lesions in other arteries supplying the brain, including intracranial stenoses. Also, we assessed endovascular technique used (type of protection, type of stent, duration of the procedure, duration of occlusion of an artery, etc.).

\section{Statistical analysis}

Continuous variables were expressed as means \pm standard deviation, categorical variables were expressed as percentages. Analysis of normality was performed with the Kolmogorov-Smirnov test. Comparison of categorical variables between the groups was performed using the $\chi^{2}$ test. Comparisons of continuous variables between the two groups were performed using the independent sample $t$-test. Multivariate, stepwise backward conditional logistic regression analysis was used to determine independent predictors of successful intervention. All significant parameters in the univariate analysis were selected in the multivariate model. The significance of the two-tailed $p$ was set at $p<0.05$. Statistical analysis was performed using the SPSS software (Statistical Package for the Social Sciences, version 23.0, SPSS Inc., Chicago, IL, USA).

\section{Results}

During 30-day follow-up there were 2 (0.5\%) fatalities. One patient died 30 days after the procedure due to intracerebral bleeding, which occurred on the $3^{\text {rd }}$ day after stenting of the carotid artery, and the other patient, who presented with severe stenosis of the aortic valve and was planned for aortic valve replacement after carotid stenting, died because of acute decompensation of the left ventricle. During 30-day follow-up there were 6 (1.5\%) strokes: 2 (0.5\%) major strokes and 4 (1.0\%) minor strokes. Regarding ipsilateral strokes, there was 1 (0.2\%) major stroke, which occurred in a patient with a history of stroke of the left hemisphere, occlusion of the left ICA, stenosis of the brachiocephalic trunk and clinical symptoms of brain stem ischemia. During the procedure this patient developed embolization of the brain stem, which occurred before the distal protection system had been introduced. Since there were contraindications for thrombolytic therapy, this patient was managed conservatively.

There were also 4 (1.0\%) minor contralateral and $1(0.2 \%)$ major contralateral stroke. The latter took place after hospital discharge, on the $5^{\text {th }}$ postprocedural day. This patient had a history of cerebral stroke in the territory of the occluded right ICA, and a new stroke developed in the same part of the brain. In the group of asymptomatic patients there were: $1(0.5 \%)$ minor stroke and 1 case of transient ischemia of the left hemisphere that 
completely resolved within $6 \mathrm{~h}$ of fibrinolytic therapy. In the group of symptomatic patients there were: $3(1.4 \%)$ minor strokes and 2 (0.9\%) major strokes, 1 ipsilateral and the other contralateral. Transient ischemic attacks occurred in 5 (1.2\%) patients, 2 such events in asymptomatic patients and 3 in symptomatic ones.

Patients who developed contralateral strokes, before the procedure, were diagnosed with stenoses and occlusions of other arteries supplying the brain. In 2 such cases strokes were probably of hemodynamic mechanism and could have developed due to the steal phenomenon: an improvement of perfusion in the territory of the revascularized artery and simultaneous deterioration of cerebral flow in the territory supplied by another, already compromised artery. In both these patients neurological symptoms resolved, respectively, after 6 and 9 days.

There was 1 (0.2\%) case of postprocedural hyperperfusion syndrome. This patient, who presented with bilateral critical stenosis of the ICAs, developed this syndrome after successful revascularization of the left ICA. Conservative management resulted in complete resolution of neurological symptoms after 5 days. After one month this patient underwent successful revascularization of the contralateral artery. Nine (2.2\%) patients developed neurological symptoms after introduction of the protection system, which probably resulted from carotid artery spasm or cerebral flow impairment in a case of occlusion of the contralateral artery. Such intolerance occurred in 3 patients managed with proximal protection and 6 patients managed with distal protection. Still, the intolerance was of no further clinical consequence, and at 30- day follow-up all these patients were free of neurological symptoms.

There were 2 (1.0\%) non-STEMI myocardial infarctions in asymptomatic patients. In both of them elective coronary bypass grafting was planned after carotid stenting, and because of this complication urgent coronary angioplasty, with implantation of drug-eluting stents, was performed, with no further significant adverse events. After the procedure 19 (9.6\%) asymptomatic and 31 (14.7\%) symptomatic patients developed hypotension, which required intravenous administration of dopamine, yet did not result in further clinical sequelae.

Details regarding complications in asymptomatic and symptomatic patients are given in Table V. Of note, there were no statistically significant differences between these groups of patients.

Logistic multivariate analysis revealed a number of risk factors predisposing to postprocedural stroke and/or death. Some of these factors, such as bilateral stenosis of the ICA, applied both to asymptomatic and symptomatic patients. Other factors seemed to be unique for the particular group. Details are given in Table VI.

\section{Discussion}

There is a high divergence of published trials on endovascular treatment of carotid artery stenosis in terms of safety and efficacy of these procedures. These results particularly differ between the centers with a high expertise in carotid stenting and those centers that participated in randomized controlled trials (doctors from the latter centers are usually more experienced in conduct-

Table V. Complications in asymptomatic vs. symptomatic patients

\begin{tabular}{|c|c|c|c|}
\hline Complications during 30-day follow-up & $\begin{array}{l}\text { Asymptomatic patients } \\
\text { (197 procedures) }\end{array}$ & $\begin{array}{l}\text { Symptomatic patients } \\
\text { (211 procedures) }\end{array}$ & $P$-value \\
\hline Ipsilateral major stroke & 0 & 1 & NS \\
\hline Contralateral major stroke & 0 & 1 & NS \\
\hline Ipsilateral minor stroke & 0 & 0 & NS \\
\hline Contralateral minor stroke & 1 & 3 & NS \\
\hline $\begin{array}{l}\text { Intraprocedural embolism of intracranial arteries } \\
\text { (managed endovascularly) }\end{array}$ & 0 & 1 & NS \\
\hline Transient cerebral ischemia, managed with fibrinolytic agents & 1 & 0 & NS \\
\hline Transient ischemic attack & 2 & 3 & NS \\
\hline Intracranial bleeding (fatal) & 1 & 0 & NS \\
\hline Subarachnoid bleeding (non-fatal) & 0 & 1 & NS \\
\hline Hyperperfusion syndrome & 1 & 0 & NS \\
\hline Myocardial infarction, managed with percutaneous carotid angioplasty & 2 & 0 & NS \\
\hline Myocardial infarction, managed conservatively & 0 & 0 & NS \\
\hline All fatalities during 30-day follow-up & 2 & 0 & NS \\
\hline
\end{tabular}

NS - difference statistically not significant. 
Table VI. Risk factors associated with postprocedural complications (strokes and/or death) revealed by logistic multivariate analysis in asymptomatic vs. symptomatic patients

\begin{tabular}{|c|c|c|c|c|c|}
\hline \multicolumn{3}{|c|}{ Asymptomatic patients (197 procedures) } & \multicolumn{3}{|c|}{ Symptomatic patients (211 procedures) } \\
\hline Risk factor & $\begin{array}{l}\text { Hazard } \\
\text { ratio }\end{array}$ & $P$-value & Risk factor & $\begin{array}{l}\text { Hazard } \\
\text { ratio }\end{array}$ & $P$ - value \\
\hline Diabetes mellitus type 2 & 26.27 & 0.001 & Diabetes mellitus type 2 & 12.10 & 0.017 \\
\hline $\begin{array}{c}\text { Stenosis localized in tortuous segment } \\
\text { of the artery }\end{array}$ & 10.74 & 0.005 & $\begin{array}{c}\text { Stenosis localized in tortuous segment } \\
\text { of the artery }\end{array}$ & 4.91 & 0.027 \\
\hline Presence of embolic material in the filter & 6.95 & 0.008 & Presence of embolic material in the filter & 5.75 & 0.016 \\
\hline $\begin{array}{l}\text { Bilateral stenoses of the internal carotid } \\
\text { artery }\end{array}$ & 4.36 & 0.037 & $\begin{array}{l}\text { Bilateral stenoses of the internal carotid } \\
\text { artery }\end{array}$ & 7.41 & 0.006 \\
\hline Renal impairment & 6.06 & 0.014 & Grade 3 arterial hypertension & 10.30 & 0.016 \\
\hline \multirow[t]{3}{*}{ Advanced coronary artery disease } & 4.06 & 0.044 & Cigarette smoking & 5.29 & 0.021 \\
\hline & & & Lesion requiring predilatation & 4.88 & 0.027 \\
\hline & & & Dislipidemia & 4.82 & 0.028 \\
\hline
\end{tabular}

ing a trial, but not necessarily regarding technical skills) $[5-7,9,10]$. While centers participating in the trials reported 30-day complication rates at the level of $2-5 \%$ in asymptomatic patients, and even as high as $10.9 \%$ in symptomatic individuals [8-13], such rates reported by highly experienced centers were: $0.9-2.4 \%$ for stroke and/or death in all patients, $0.4-2.3 \%$ in asymptomatic and $1.1-3.5 \%$ in symptomatic patients [5-7, 14]. Our data are similar to the latter centers: the 30-day rate of stroke and/or death was $2.0 \%$, and the stroke rate was $1.5 \%$. The stroke rate in asymptomatic patients was $0.5 \%$, and in symptomatic ones $2.4 \%$. Of note, many of our patients suffered from severe vascular disease: approximately $50 \%$ of patients presented with bilateral lesions in the carotid arteries, including $14 \%$ of them with occlusion of one of the ICAs, and $9 \%$ of patients had high grade or occlusion of the vertebral artery.

In each patient we carefully tailored the technique and armamentarium used, respecting anatomy of the arteries and location of the lesions. The proximal protection system was preferred, and even in technically difficult cases there were no complications associated with the use of this type of protection. In order to minimize the likelihood of adverse events, when using proximal protection, complete closure of the common carotid artery was postponed until the guidewire and stent had been introduced to the distal part of the system. The total rate of intolerance of proximal protection was 3.0\%.

Such a low incidence of adverse events is in line with the results of other researchers $[8,15]$. In 2 cases we applied both distal and proximal protection. Such management of a complex pathology has already been revealed to be safe $[16,17]$.

In addition to proper choice of the protection system, stents should be tailored to the lesion. Stenoses located in proximal parts of the common carotid artery or vertebral arteries, as well as those of the subclavian arteries, were managed using balloon-expandable stents. In the case of vertebral artery lesions drug-eluting stents were preferred. Lesions in the distal parts of the common carotid arteries and in the ICAs were managed using self-expandable stents, preferentially with a closed-cell design. Closed-cell stents were used in the majority of patients. If such a stent could not be used, we opted for an open-cell stent with as small as possible size of the cells. Although we did not observe any statistically significant differences between patients' outcomes associated with the use of either close- or open-cell stents, other researchers have reported fewer complications after closed-cell devices [6, $7,18]$. Recently, a new generation of carotid stents has been marketed; these stents combine small area of the cells with flexibility characteristic for open-cell devices. Perhaps, such stents, which appear to be an interesting alternative to currently utilized devices, will further improve the results of carotid stenting $[19,20]$.

In 4 of our patients we addressed the lesions located intracranially. In all these cases the procedures were free of complications. In addition, in 3 patients we implanted carotid stents distally, up to the C4/C5 segment of the ICA. Two intracranial procedures were performed to manage complications; there was one local intra-arterial fibrinolysis and one mechanical thrombectomy. In a case of intraprocedural cerebral embolism also other researchers performed mechanical recanalization, using either stents or balloons, and such management appeared to be both safe and efficient, similarly to the treatment of intracranial lesions of the vertebral arteries [6, 7, 13, 21]. A possibility to address lesions or complications located intracranially seems to improve the safety of endovascular procedures of extracranial arteries.

Statistical analysis revealed that diabetes mellitus, tortuosity of the artery in the area of stenosis, presence of embolic material in the filter and bilateral stenoses of the ICAs were associated with an increased risk of 
postprocedural complications in both asymptomatic and symptomatic patients. Two of these risk factors are particularly associated with a potential technical failure: bilateral stenosis substantially limits the possibility to use proximal protection, while tortuosity of the artery makes the safe introduction of distal protection challenging. Other risk factors were different in asymptomatic and symptomatic groups. Details are given in Table VI. Our data are similar to the already published research, which has identified diabetes mellitus, bilateral stenoses of the carotid arteries, age of the patient more than 80 years and female sex as independent risk factors [5-7, 22-24].

Although there are some studies on carotid artery stenting where protection systems were not used [25], similarly to others $[5-7,26,27]$ we opt for obligatory use of a protection system. After the procedures we found macroscopic embolic material in filters in 20 asymptomatic and 47 symptomatic patients, and in 7 symptomatic patients there was quite a lot of such potentially dangerous debris. Also, research has demonstrated that there are fewer complications if the procedures are performed by experienced interventionalists, and there seems to be a learning curve with a significant drop in the complication rate with more than 200 procedures performed [5-7, 28, 29].

There are several limitations of this study. Firstly, this is a retrospective analysis and the patients were not randomized. Also, only early outcomes, with 30-day follow-up, were analyzed. Secondly, high heterogeneity of patients and technical details, including clinical status, anatomic location and characteristics of lesions, and endovascular armamentarium used, makes a reliable statistical analysis of data difficult. Still, analyses of such registers have already demonstrated that the use of endovascular technique tailored to the characteristics of stenosis, management of intracranial lesions and the use of novel endovascular devices can result in better results of these procedures and in acceptable complication rates.

\section{Conclusions}

Our results suggest that endovascular treatment of extracranial arteries supplying the brain, which is tailored to the type and anatomy of lesions, is a relatively safe procedure. Postprocedural complications are more common in patients presenting with several risk factors: diabetes mellitus, lesions localized in a tortuous segment of the artery, presence of embolic material in the filter and bilateral stenoses of the internal carotid artery. In addition, such adverse events were more common in asymptomatic patients presenting with renal impairment and advanced coronary artery disease. In symptomatic patients these additional risk factors were grade 3 arterial hypertension, dislipidemia, cigarette smoking and presence of lesions requiring predilatation.

\section{Conflict of interest}

The authors declare no conflict of interest.

\section{References}

1. Endarterectomy for asymptomatic carotid artery stenosis. Executive committee for the Asymptomatic Carotid Atherosclerosis Study. JAMA 1995; 273: 1421-8.

2. Barnett HJ, Taylor DW, Eliasziw M, et al. Benefit of carotid endarterectomy in patients with symptomatic moderate or severe stenosis. North American Symptomatic Carotid Endarterectomy Trial Collaborators. N Engl J Med 1998; 339: 1415-25.

3. Randomised trial of endarterectomy for recently symptomatic carotid stenosis: final results of the MRC European Carotid Surgery Trial (ECST). Lancet 1998; 351: 1379-87.

4. Halliday A, Mansfield A, Marro J, et al. Prevention of disabling and fatal strokes by successful carotid endarterectomy in patients without recent neurological symptoms: randomised controlled trial. Lancet 2004; 363: 1491-502.

5. Cremonesi A, Gieowarsingh S, Spagnolo B, et al. Safety, efficacy and long-term durability of endovascular therapy for carotid artery disease: the tailored-Carotid Artery Stenting Experience of a single high-volume centre (tailored-CASE Registry). Eurolntervention 2009; 5: 589-98.

6. Pieniążek P, Musiałek P, Kablak-Ziembicka A, et al. Carotid artery stenting with patient- and lesion-tailored selection of the neuroprotection system and stent type: early and 5-year result from a prospective academic registry of 535 consecutive procedures (TARGET-CAS). J Endovasc Ther 2008; 15: 249-62.

7. Pieniążek P, Tekieli L, Musiałek P, et al. Carotid artery stenting according to the tailored-CAS algorithm is associated with a low complication rate at 30 days: data from the TARGET-CAS study. Kardiol Pol 2012; 70: 378-86.

8. Ansel GM, Hopkins LN, Jaff MR, et al. Safety and effectiveness of the INVATEC MO.MA proximal cerebral protection device during carotid artery stenting: results from the ARMOUR pivotal trial. Catheter Cardiovasc Interv 2010; 76: 1-8.

9. Mas JL, Trinquart L, Leys D, et al. Endarterectomy versus angioplasty in patients with symptomatic severe carotid stenosis (EVA-3S) trial. Results up to 4 years from a randomised, multicentre trial. Lancet Neurol 2008; 7: 885-92.

10. Hobson RW 2nd, Howard VJ, Roubin GS, et al. Carotid artery stenting is associated with increased complications in octogenarians: 30-day stroke and death rates in the CREST lead-in phase. J Vasc Surg 2004; 40: 1106-11.

11. Vouyouka AG, Egorova NN, Sosunov EA. Analysis of Florida and New York state hospital discharges suggests that carotid stenting in symptomatic women is associated with significant increase in mortality and perioperative morbidity compared with carotid endarterectomy. J Vasc Surg 2012; 56: 334-42.

12. Massop D, Dave R, Metzger C, et al. SAPPHIRE Worldwide Investigators, Stenting and angioplasty with protection in patients at high-risk for endarterectomy: SAPPHIRE Worldwide Registry first 2,001 patients. Catheter Cardiovasc Interv 2009; 73: 129-36.

13. Campbell BC, Hill MD, Rubiera M, et al. Safety and efficacy of Solitaire stent thrombectomy: individual patient data metaanalysis of randomized trials. Stroke 2016; 47: 798-806.

14. Stabile E, Garg P, Cremonesi A, et al. European Registry of Carotid Artery Stenting: results from a prospective registry of eight high volume EUROPEAN institutions. Catheter Cardiovasc Interv 2012; 80: 329-34. 
15. Clair DG, Hopkins LN, Mehta M, et al. Neuroprotection during carotid artery stenting using the GORE flow reversal system: 30day outcomes in the EMPiRE Clinical Study. Catheter Cardiovasc Interv 2011; 77: 420-9.

16. Latacz P, Ochała A, Janas P, et al. Composed angioplasty of the multilevel right common and internal carotid artery stenoses with implantation stents with used of proximal and distal protection system. Kardiol Pol 2012; 70: 88-90.

17. Kajihara Y, Sakamoto S, Kiura Y. Comparison of dual protection and distal filter protection as a distal embolic protection method during carotid artery stenting: a single-center carotid artery stenting experience. Neurosurg Rev 2015; 38: 671-6.

18. Kouvelos GN, Patelis N, Antoniou GA. Meta-analysis of the effect of stent design on 30-day outcome after carotid artery stenting. J Endovasc Ther 2015; 22: 789-97.

19. Setacci C, Speziale F, De Donato G. Physician-initiated prospective Italian Registry of carotid stenting with the C-Guard meshstent: the IRON-Guard registry. Rationale and design. J Cardiovasc Surg (Torino) 2015; 56: 787-91.

20. Hopf-Jensen S, Marques L, Preiß M, et al. Initial clinical experience with the micromesh roadsaver carotid artery stent for the treatment of patients with symptomatic carotid artery disease. J Endovasc Ther 2015; 22: 220-5.

21. Yin R, Chang F, Hong B. Stenting for symptomatic intracranial vertebrobasilar artery stenosis: 30-day results in a high-volume stroke center. Clin Neurol Neurosurg 2016; 143: 132-8.

22. Moore WS, Popma JJ, Roubin GS, et al. Carotid angiographic characteristics in the CREST trial were major contributors to periprocedural stroke and death differences between carotid artery stenting and carotid endarterectomy. J Vasc Surg 2016; 63: 851-8.e1

23. Doig D, Turner EL, Dobson J, et al. Predictors of stroke, myocardial infarction or death within 30 days of carotid artery stenting: results from the International Carotid Stenting Study. Eur J Vasc Endovasc Surg 2016; 51: 327-34.

24. Khan M, Qureshi Al. Factors associated with increased rates of post-procedural stroke or death following carotid artery stent placement: a systematic review. J Vasc Interv Neurol 2014; 7: 11-20.

25. Pandey AS, Koebbe CJ, Liebman K, et al. Low incidence of symptomatic strokes after carotid stenting without embolization protection devices for extracranial carotid stenosis: a single-institution retrospective review. Neurosurgery 2008; 63: 867-72.

26. Reimers B, Schluter M, Castriota F, et al. Routine use of cerebral protection during carotid artery stenting: results of a multicenter registry of 753 patients. Am J Med 2004; 116: 217-22.

27. Eckstein $H H$, Ringleb P, Allenberg JR, et al. Results of the stent-protected angioplasty versus carotid endarterectomy (SPACE) study to treat symptomatic stenoses at 2 years: a multinational, prospective, randomised trial. Lancet Neurol 2008; 7: 893-902.

28. Ielasi A, Latib A, Cosmo Godino C, et al. Clinical outcomes following protected carotid artery stenting in symptomatic and asymptomatic patients. J Endovasc Ther 2010; 17: 298-307.

29. Shishehbor MH, Venkatachalam S, Gray WA, et al. Experience and outcomes with carotid artery stenting: an analysis of the CHOICE study (Carotid Stenting for High Surgical-Risk Patients; Evaluating Outcomes Through the Collection of Clinical Evidence). JACC Cardiovasc Interv 2014; 7: 1307-17. 